Hughes, W. Howard (1952). J. gen. Microbiol. 6, 175-180

\title{
Variation in Penicillin Resistance in Single-cell Gultures of Staphylococcus aureus
}

\author{
By W. HOWARD HUGHES \\ The Bacteriological Department, Wright-Fleming Institute, St Mary's \\ Hospital Medical School, London, W. 2
}

SUMMARY: Using staphylococci grown from single-cell isolations made at various stages of selection on penicillin media, it was observed that the $18 \mathrm{hr}$. progeny show variations in penicillin sensitivity, as tested by increase in resistance. The range of variation is about the same at any stage in selection; variation appears to be continuous in any one population of the microbes, since the number showing increased resistance depends upon the closeness of the steps in penicillin concentration used in testing the resistance.

There does not yet appear to be sufficient evidence on the frequency of variation in pure strains of organisms; the following investigations were undertaken to discover whether penicillin resistant variants appear in strains grown from single cells and in which therefore no possibility of crossing between genetically different individuals, such as was described by Tatum \& Lederberg (1947), exists.

\section{EXPERIMENTAL}

A strain of coagulase-positive Staphylococcus aureus was obtained from a previously unopened abscess in a patient who had never been treated with penicillin. A single colony from the primary growth was subcultured and a second well-isolated colony selected as the parent strain of the series. From a young culture of this strain $\mathbf{P}$ two single cocci were isolated by the micromanipulator to form the first generation; these are I and II respectively (Fig. 1). The three strains P, I and II were identical by phage-typing (Williams, 1950).

\section{Method 1}

The three strains were examined for penicillin sensitivity by seeding on to a series of agar media containing concentrations of penicillin increasing by $\frac{1}{400}$ unit/ml. The daughter strains I and II differed in penicillin sensitivity by this amount, I being as resistant as $\mathbf{P}$ and II more resistant than either. The difference was shown not only by the end-point of the titration, but also by colony size with partially inhibitory penicillin concentrations; the colonies of II were larger than those of I.

With implants of about 100 organisms the titration gave a sharp end-point; there was no evidence of scatter of sensitivity that could not be accounted for by the experimental error of the method. When however the concentrations of penicillin differed by only $\frac{1}{1200} \mathrm{unit} / \mathrm{ml}$. from one plate to the next, small but real differences in sensitivity were observed in colonies from one inoculum.

When the size of implant was increased considerably some cells survived 
and grew at higher concentrations of penicillin than was the case with the small inoculum. This phenomenon has long been known (see Florey, 1949), but in the present experiments a regular relationship between the size of implant and the number of colonies developing was also noted, namely, that for every tenfold increase in implant there was a $40 \%$ increase of resistance as judged by the final concentration on which any colonies appeared. Quantitative tests by a tube method were made to confirm this finding.

\section{Method 2}

The tube method was based on that used for presumptive coliform count (Ministry of Health, 1939) and at first the McCready tables, suitably modified, were used. As, however, more data were available than is usual in coliform tests the number of survivors was calculated from table VIII, 2, of Fisher \& Yates (1948). The test consisted of quintuplicate titrations, using eight serial tenfold dilutions of an $18 \mathrm{hr}$. broth culture, made from a stock kept at $4^{\circ}$ in Robertson's meat medium following its isolation and growth from the single cell. To avoid clumps the suspension was shaken mechanically and then allowed to stand, the upper layers being taken for use. To $0.05 \mathrm{ml}$. lots of the eight dilutions $\left(10^{0}-10^{-7}\right) 2.5 \mathrm{ml}$. of the penicillin solution in broth was added and each of the mixtures was then distributed among the five tubes forming a quintuplicate set with $0.01 \mathrm{ml}$. of the suspension in $0.5 \mathrm{ml}$. penicillin solution in each. The cultures were tested with eleven penicillin concentrations and one control series in broth alone. The number of organisms in the inoculum was estimated by plate counts. It would be possible to dispense with this if the culture were serially diluted so as to be sterile at the end of the series, since the calculation is most accurate when there are groups of tubes without growth.

Table 1 shows one complete titration and column 10 the frequency of

Table 1. Specimen tube titration showing variations in sensitivity of single-cell strain $X X X$ of Staph. aureus

\begin{tabular}{|c|c|c|c|c|c|c|c|c|c|}
\hline \multirow{3}{*}{$\begin{array}{l}\text { Penicillin } \\
\text { concen- } \\
\text { tration } \\
\text { (u. } / \mathrm{ml} .)\end{array}$} & \multicolumn{8}{|c|}{ Dilutions of culture } & \multirow{3}{*}{$\begin{array}{l}\text { Estimated } \\
\text { no. of } \\
\text { survivors/ } \\
10^{6} \\
\text { implanted }\end{array}$} \\
\hline & $10^{\circ}$ & $10^{-1}$ & $10^{-2}$ & $10^{-3}$ & $10^{-4}$ & $10^{-5}$ & $10^{-6}$ & $10^{-7}$ & \\
\hline & \multicolumn{8}{|c|}{ No. of tubes positive/group of five } & \\
\hline $0 \cdot 000$ & . & . & . & . & 5 & 5 & 5 & 5 & . \\
\hline $0 \cdot 125$ & - & - & - & . & 5 & 5 & 5 & $\mathbf{5}$ & . \\
\hline $0 \cdot 15$ & . & . & - & - & 5 & 5 & 5 & 5 & . \\
\hline $0 \cdot 2$ & . & . & . & . & 5 & $\mathbf{5}$ & $\mathbf{5}$ & $\mathbf{5}$ & . \\
\hline 0.25 & - & . & . & . & $\mathbf{5}$ & 5 & 5 & 5 & . \\
\hline $0 \cdot 375$ & - & - & - & - & 5 & $\mathbf{5}$ & 5 & 5 & . \\
\hline 0.5 & . & . & . & . & 5 & $\mathbf{5}$ & 5 & 5 & . \\
\hline 0.625 & - & . & . & 5 & 5 & 5 & 5 & 3 & 290,000 \\
\hline $0 \cdot 75$ & . & . & 5 & $\mathbf{5}$ & 5 & $\mathbf{3}$ & 1 & 0 & 44,000 \\
\hline 0.875 & . & 5 & 5 & 5 & $\mathbf{3}$ & 0 & $\mathbf{0}$ & $\mathbf{0}$ & 285 \\
\hline 1.0 & 5 & 5 & 5 & 5 & o & 0 & $\mathbf{0}$ & $\mathbf{0}$ & 66 \\
\hline $\mathbf{1 \cdot 2 5}$ & 5 & 5 & 4 & 2 & 1 & 0 & 0 & $\mathbf{0}$ & 77 \\
\hline $\begin{array}{l}\text { Inoculum } \\
\text { estimated }\end{array}$ & $6 \times 10^{6}$ & $26 \times 10^{5}$ & 260,000 & 26,000 & 2,600 & 260 & 26 & $4 \cdot 25$ & \\
\hline
\end{tabular}


survivors/million implant. It is to be noted that here, as in Demerec's work (1948), the penicillin is used to detect variation in resistance and not to induce it.

Further subcultures of the survivors were made, and grown without penicillin; from these cultures single cells were picked and the distribution of the sensitivities determined in the populations derived from them. The derivation of the strains was as follows:

$$
\begin{aligned}
& \text { Parent culture }\left\{\begin{array}{l}
\text { Single colony strain } \\
\text { Single cells }
\end{array}\right. \\
& \mathrm{S}_{1}\left\{\begin{array}{l}
\text { Single colonies } \\
\text { Single cells }
\end{array}\right. \\
& \mathrm{S}_{\mathbf{2}}\left\{\begin{array}{l}
\text { Single colony } \\
\text { Single cells }
\end{array}\right. \\
& \mathrm{S}_{\mathbf{3}}\left\{\begin{array}{l}
\text { Single colony } \\
\text { Single cell }
\end{array}\right. \\
& \mathrm{S}_{4} \text { Single colony }
\end{aligned}
$$

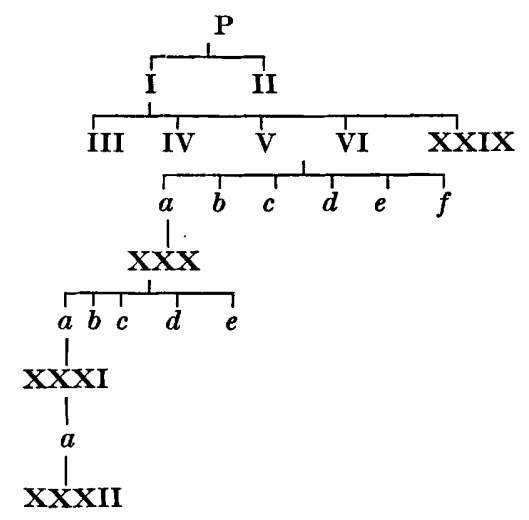

The results with four single-cell cultures, one from each subculture, are shown in Fig. 2 the log number of survivors being plotted against the log dose of penicillin. The curves are approximately linear and parallel. Usually several separate cells were taken in each of the generations and all gave the same type of curve; but the position of this curve varied considerably with each single coccus even in the same subculture.

The findings recorded in Fig. 2 suggest that there is a definite ratio by which the penicillin resistance increases in each subculture. But the truth of this deduction is restricted to the conditions of the experiment, since it is by the selection of the most resistant members of the population that this result is achieved. There have been in each subculture cells which were less resistant than those whose resistance is recorded in the graph.

The finding that a bacterial cell has survived exposure to a certain concentration of penicillin is no guarantee that single cells picked from its progeny will give populations of the same or greater resistance; as soon as growth is allowed to take place on normal media the variation of sensitivity will be resumed in both directions and thereafter a cell that is less resistant than the parent may be picked instead of a more resistant one. Variants of diminished resistance are quite common; e.g. of 15 single-cell strains derived directly or indirectly from strain I three more sensitive than the cell giving rise to the colony from which they were picked. Two of these were more sensitive than any in the previous generation; they were in fact sensitive to $0.075 \mathrm{unit} / \mathrm{ml}$. as compared with the colony from which they came (2.0 units $/ \mathrm{ml}$.) and with the previous subculture $(0 \cdot 125$ unit/ml.). The strains were tested for extracellular penicillinase production but this had not developed in any of them.

G M VI I, 2 


\section{DISCUSSION}

From the evidence it is clear that single cells give rise, on overnight culture, to populations containing individuals differing to a considerable degree from the parent. For one characteristic, penicillin sensitivity, variation is of the same sort whether the strain has been exposed to the drug or not; the population derived from strain $I$, as characterized by the survivor dose curve, is similar to that from strain XXXI which had been selected three times for increased resistance.

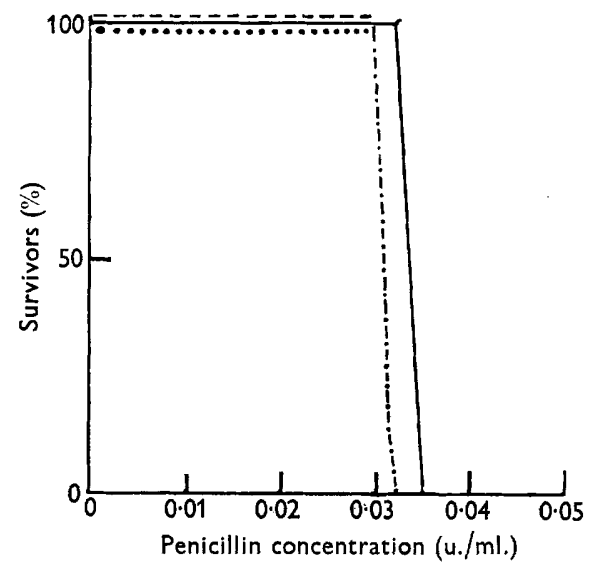

Fig. 1

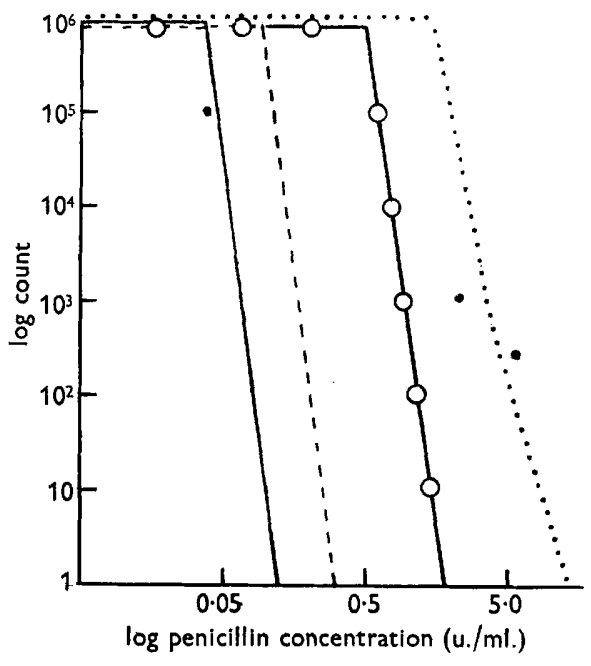

Fig. 2

Fig. 1. Titration of sensitivity of single-cell strains of staphylococci using small implants. Key to curves: - - , parent strain; ...., single-cell strain I; . - . - , single-cell strain II. Parent strain and strain I give a value of $0.0325 \mathrm{u} . / \mathrm{ml}$. for $0 \%$ survivors. Strain II gives a value of $0.035 \mathrm{u} . / \mathrm{ml}$. under identical conditions.

Fig. 2. Results of tube titration of sensitivity of single-cell strains of staphylococci. Key to curves: -—, strain I; - - , strain VI $a$; $-\mathrm{O}-$, strain XXX $a ; \ldots \ldots$, strain XXXI $a$. The four subcultures show a similar distribution of sensitivity, although the average sensitivity of each is at a different level. Each curve on this graph is built up from 11 separate points, the only 3 points not falling on their line are marked 0 .

The term used to describe this type of variation needs careful consideration. They do not form a genetically uniform clone. The term mutation is also applied to the kind of variation we are considering. Demerec (1948) cautiously suggested that the rate of mutation to resistance might be of the order of one in $10^{8}$ cells.

Such a resistant variant can be selected, but if it should be styled a mutant then so should strain II which differs from the P and I strains by only $\frac{1}{400}$ of a unit; so too should each of the five cells forming the third series (XXX, $a-e)$, all of which differed from the parent of the colony from which they were isolated and only two of which had the same resistance. In the plate method of titration, differences of up to $10 \%$ in the count may be due to sampling error 
and an error of this size would easily obscure fine differences. It can be inferred from the populations raised from the single cells that about this proportion of cells are detectably more resistant than the average.

The method of recording results on a log scale, necessitated by the size of the populations, obscures any change at the 'more sensitive' part of the scale. It cannot, therefore, be proved whether there are as many individual cells more sensitive than the average as there are more resistant ones. Yet many such individuals are present, for they may be picked accidentally from a population, the mean resistance of which is high. Also where the parent cell has been isolated in the presence of particular concentrations of penicillin and not from a culture in normal media, the sensitivity of that single cell is likely to be resistant to the 'isolating' concentration, yet the population derived from it contains cells sensitive to less than this concentration. No method exists, however, for detecting very rare variants with greatly increased sensitivity.

Similar high rates have been reported for the mutation of $\mathbf{H}$ antigens in Salmonella typhimurium (Stocker, 1949). Deskowitz \& Shapiro (1935) found an $\mathbf{R}$ variant giving $17 \% \mathrm{~S}$ colonies on solid medium.

Segregation on strict mendelian lines as an explanation of this variation also presents difficulties; if we start with a single cell and it is assumed that no new genetic material can be introduced, any redistribution of nuclear material must be by autogamy. Even if the cell were heterozygous the repeated reselection employed would give a uniform population by the fourth subculture.

If we are to be driven to use the term mutation then we are using it in a sense not usually employed by workers in other fields and have to accept a rate of mutation of as high as one in ten. Whatever we may call the variation it is continuous and not discontinuous for the particular characteristic studied, and by the end of the thirty generations, represented by the $18 \mathrm{hr}$. cultures sampled in these experiments, a regular distribution has been reached. It may well be that the exact interpretation will depend on the correlation of these and similar results with the cytological studies of microbial division and on breeding experiments like those of Tatum \& Lederberg (1947) and Zelle \& Lederberg (1951).

One other conception must be examined in the light of these results. Superficially the upper parts of the curves in Fig. 2 and the whole of Fig. 1 closely resembles Demerec's figures (1948), though he did not start with single cells but used a stock strain; nevertheless, these two figures are to some extent artefacts and so by implication is the idea of stepwise variation. The size of the step is limited only by the practicable implant and not by any inherent characteristics in the cells. The number of steps that could be interposed seems almost limitless, since, once the critical level has been reached where any members of a population are inhibited, a small increase in penicillin concentration will decrease the numbers of survivors, and from these, populations can be raised which differ from the original parent strain either by little or much, depending on the exact point at which selection was made. It seems clear that within the individual staphylococcus is a capacity for variation much 
greater than has been supposed. In its flexibility it behaves in a way not anticipated either from simple fission into two identical units or from the laws of inheritance postulated for plants and animals.

My thanks are due to Dr A. Voureka for providing single-cell cultures for two of the generations of staphylococci and to Dr R. E. O. Williams for the phage typing.

\section{REFERENCES}

Demerec, M. (1948). Origin of bacterial resistance to antibiotics. J. Bact. 56, 63 . Deskowitz, M. \& Shapiro, A. (1935). Numerical relations of unstable variant of Salmonella aertrycke. Proc. Soc. Exp. Biol., N.Y., 32, 573.

Fisher, R. A. \& Y YTES, F. (1948). Statistical Tables, 3rd ed. London: Oliver and Boyd.

Floney, H. W., Ed. (1949). Antibiotics. London: Oxford University Press.

Ministry of Health (1939). Report No. 71. London: H.M. Stat. Office.

STOckER, B. A. D. (1949). Measurement of rate of mutation of flagella antigenic phase in Salmonella typhi-murium. J. Hyg., Camb., 47, 398.

TAtum, E. L. \& Lederberg, J. (1947). Gene recombination in the bacterium Escherichia coli. J. Bact. 53, 673.

Williams, R. E. O. (1950). Personal communication.

ZELLE, M. R. \& LEDERBERG, J. (1951). Single-cell isolations of diploid heterozygous Escherichia coli. J. Bact. 61, 351.

(Received 21 August 1951) 